\title{
Pengaruh Persentase Massa Gipsum Dan Serat Terhadap Kuat Tekan Dan Kuat Lentur Papan Semen - Gipsum Berserat Eceng Gondok
}

\author{
Ummi Qorina*, Alimin Mahyudin, Sri Handani \\ Jurusan Fisika, FMIPA, Universitas Andalas, Kampus Limau Manis Padang, 25153 \\ *qorina679@gmail.com
}

\begin{abstract}
ABSTRAK
Telah dilakukan penelitian tentang pengaruh persentase massa gipsum dan serat terhadap kuat tekan dan kuat lentur papan semen-gipsum berserat eceng gondok. Alat uji Kuat tekan dan kuat lentur diukur menggunakan universal testing machine (UTM). Dari hasil pengujian terhadap papan semen-gipsum dengan persentase massa serat tetap 2,5\% diperoleh nilai kuat tekan paling tinggi yaitu sebesar 14,52 $\mathrm{kg} / \mathrm{cm}^{2}$ pada persentase massa gipsum $30 \%$. Sedangkan pada papan semen-gipsum dengan persentase massa gipsum tetap $30 \%$ diperoleh nilai kuat tekan tertinggi sebesar $24,99 \mathrm{~kg} / \mathrm{cm}^{2}$ pada persentase massa serat 7,5\%. Hasil pengujian terhadap papan semen-gipsum dengan persentase massa serat tetap $2,5 \%$ diperoleh nilai kuat lentur paling tinggi yaitu sebesar $1,265 \mathrm{~kg} / \mathrm{cm}^{2}$ pada persentase massa gipsum $30 \%$. Sedangkan pada papan semen-gipsum dengan persentase massa gipsum tetap $30 \%$ diperoleh nilai lentur tertinggi sebesar $1,575 \mathrm{~kg} / \mathrm{cm}^{2}$ pada persentase massa serat $5 \%$.

Kata kunci: papan semen-gipsum, serat eceng gondok, kuat tekan dan kuat lentur.
\end{abstract}

\begin{abstract}
The research about the influence of mass percentage of gypsum and fibers to compressive and flexural strength of gypsum-cement board with water hyacinth fiber has been conducted. The compressive and flexural strength were measured using universal testing machine (UTM). The result shows that the board with constant mass percentage of water hyacinth fiber of $2.5 \%$ have maximum value of compressive strength $\left(14.52 \mathrm{~kg} / \mathrm{cm}^{2}\right)$ and of flexural strength $\left(1.265 \mathrm{~kg} / \mathrm{cm}^{2}\right)$ both at $30 \%$ of gypsum mass percentage. The board with constant mass percentage of gypsum mass of $30 \%$ have maximum value of compressive strength $\left(24.99 \mathrm{~kg} / \mathrm{cm}^{2}\right.$ ) at $30 \%$ of water hyacinth fiber percentage $7.5 \%$ and of flexural strength $\left(1.575 \mathrm{~kg} / \mathrm{cm}^{2}\right)$ at water hyacinth fiber percentage of $5 \%$.

Keywords: gypsum-cement board, hyacinth fiber, compressive strength, flexural strength.
\end{abstract}

\section{PENDAHULUAN}

Papan semen adalah papan tiruan yang terbuat dari campuran partikel kayu atau bahan berlignoselulosa, semen dan bahan tambahan. Papan semen memiliki kelebihan antara lain: tahan terhadap jamur, serangga, api, kelembaban serta memiliki stabilitas dimensi yang tinggi. Berdasarkan perkembangan sampai saat ini, papan semen juga memiliki masalah dimana waktu pengerasan semen yang relatif lama yakni minimal 28 hari ( \pm 1 bulan) dan merupakan jenis panel yang cukup berat (Nugraha dan Antoni, 2007).

Pengerasan semen yang relatif lama pada papan semen dapat diatasi dengan penambahan gipsum, Gipsum mempunyai sifat yang cepat mengeras yaitu sekitar 10 menit (Simatupang, 1989) Penambahan serat yang memiliki bobot ringan, mempunyai kekuatan dan kekakuan yang baik serta produksi yang murah dan tahan korosi dapat mengatasi kekurangan papan semen yang cukup berat (Smallman dan Bishop, 2000). Salah satu serat yang dapat digunakan dalam pembuatan papan semen adalah eceng gondok. Eceng gondok sangat melimpah untuk dijadikan sebagai bahan baku pembuatan plafon. Umumnya industri komposit yang berhubungan dengan serat (terutama serat alam) tidak banyak diberitakan di Indonesia karena sebagian besar didominasi oleh serat karbon (carbon fibre) atau serat kaca (glass fiber). Maka dari itu, penelitian tentang komposit serat alam mulai dikembangkan sebagai bahan alternatif yang ramah lingkungan (Roseno, 2003).

Papan semen-gipsum yang sering digunakan sebagai partisi bagunan, langit-langit rumah seperti pada GRC board yang berkembang dipasaran. GRC board (Glass-Fiber Reinforced Cement) adalah papan semen fiber-glass yang ringan, tahan kelembaban dan tidak mudah lapuk. GRC board tidak dapat terbakar (sesuai dengan hasil tes BS 476, Part 4:1970). Ukuran standar yang tersedia yaitu: $1220 \mathrm{~mm}$ x $2440 \mathrm{~mm}$ dengan ketebalan 5,6,8 dan $10 \mathrm{~mm}$ (Nugraha dan Antoni, 2007). 
Prasetyo (2006) tentang pembuatan material baru papan semen berserat eceng gondok. Hasil penelitian menunjukkan bahwa nilai kerapatan rata-rata contoh uji OSB memenuhi standar pada semua perlakuan berdasarkan Japanese Industrial Standart (JIS) A 5908-2003, untuk nilai kadar air Oriented Strand Board (OSB) ditetapkan sebesar 5-13\%. Sedangkan untuk arah tekan sejajar panjang dan lebar serta kekuatan lentur belum memenuhi standar JIS A 59082003. Berdasarkan Standar Food and Agriculture Organization (FAO), eceng gondok dengan panjang batang $11,65 \mathrm{~mm}$ mengandung air yang ber-nutrien tinggi, seperti nitrogen, fosfat dan potasium, dan SNI 03-6861.1-2002 adalah $110-1250 \mathrm{~kg} / \mathrm{cm}^{3}$.

Kahfi (2007) telah melakukan penelitian papan semen-gipsum dengan penambahan serat tandan kosong kelapa sawit. Hasil penelitian menunjukkan bahwa fisis papan yang dihasilkan memenuhi standar JIS A 5908-2003, standar FAO adalah kerapatan dan pengembangan tebal $0,67 \mathrm{~g} / \mathrm{cm}^{3}$ dan SNI 03-6384-2000 untuk nilai daya serap yaitu sebesar 19,97-32,19\% sedangkan untuk densitas dan kekuatan belum memenuhi ketiga standar tersebut.

Prasetyo (2009) telah melakukan penelitian daktilisasi panel semen eceng gondok. Penelitian ini merupakan penelitian lanjutan untuk mengetahui karakteristik bahan bangunan berupa dinding panel eceng gondok. Dari kajian terdahulu, sifat fisik, mekanik, akustik dan ketahanan bakar material ini memenuhi standar bahan bangunan PUBI 1982 dan SNI 036861.1-2002 dan Standards and Literature References For Composite Materials (ASTM) C42390a. Faktor daktilitas simpangan rata-rata sebesar 15,04 mm dan daktilitas kelengkungan ratarata adalah $17,10 \mathrm{~mm}$ maka jenis keruntuhan material dinding panel eceng gondok adalah bersifat daktail. Ketersediaan serat eceng gondok sebagai bahan baku serat alam untuk material komposit cukup melimpah (Prasetyaningrum, dkk., 2009). Penelitian ini dilakukan untuk mengetahui nilai kuat tekan dan kuat lentur papan semen-gipsum berserat eceng gondok.

\section{METODE}

Penelitian ini dilaksanakan pada bulan Januari sampai April 2016. Pembuatan sampel papan semen-gipsum dilakukan di Laboratorium Fisika Material Jurusan Fisika Universitas Andalas. Sedangkan pengujian kuat tekan dan lentur dilakukan di laboratorium Mekanik Politehnik Negeri Padang. Peralatan yang digunakan adalah gelas ukur, spatula, oven, cawan porselin, sekop kecil, ayakan 50 mesh, timbangan digital, cetakan papan beton dan Universal Testing Machine (UTM). Bahan yang digunakan adalah tepung gipsum, semen, serat eceng gondok, air, dan agregat halus (pasir).

Mula-mula eceng gondok dikeringkan menggunakan oven selama 3 jam setelah itu serat eceng gondok dipisahkan dengan batangnya menggunakan jarum pentul. Agregat halus berupa pasir sungai, pasir yang sudah kering digerus dan disaring menggunakan ayakan 50 mesh. Serat eceng gondok, semen, gipsum, pasir ditimbang dengan menggunakan neraca digital. Semen dan pasir (pasta beton) diaduk didalam wadah dengan menambahkan air (aquades) sampai kental,dituangkan kedalam cetakan yang berukuran $(20 \mathrm{~cm} \times 10 \mathrm{~cm} \times 1 \mathrm{~cm})$ utuk uji kuat lentur, sedangkan uji kuat tekan berukuran $(5 \mathrm{~cm}$ x $5 \mathrm{~cm}$ x $5 \mathrm{~cm})$. Setelah itu disusun serat dengan arah three dimensional reinforcement (secara acak), dituangkan kembali adukan pasta beton diatas cetakan yang diberi serat, ditunggu sampai 2 jam. Setelah cetakan mulai kering dilanjutkan dengan adukan gipsum yang diberi air (aquades) dan dituangkan dilapisan atas dan bawah. Cetakan didiamkan selama 14 hari lalu papan beton yang terbentuk dikeluarkan dari cetakan. Papan beton yang sudah dipisahkan dari cetakan, ditimbang dengan neraca digital. Pengujian kuat tekan dan kuat lentur menggunakan alat berupa universal testing machine (UTM). Hasilnya dibandingkan dengan standar seperti terlihat pada Tabel 1.

Tabel 1 Karakteristik papan beton standar mutu FAO, JIS 5908-2003, Bison Gypsum Fiber Board dan SNI 03-6384-2000 untuk papan komposit.

\begin{tabular}{cccccc}
\hline \multirow{2}{*}{$\begin{array}{c}\text { Sifat } \\
\text { Mekanik }\end{array}$} & Satuan & FAO & JIS 5908-2003 & $\begin{array}{c}\text { Bison Gypsum } \\
\text { Fibre Board }\end{array}$ & SNI \\
\cline { 2 - 6 } & & $100-500$ & $82-184$ & 53,9 & Min 18 \\
Kuat tekan & $\mathrm{kg} / \mathrm{cm}^{2}$ & $10000-50000$ & $20400-36000$ & 28,44 & Min 15000 \\
Kuat lentur & $\mathrm{kg} / \mathrm{cm}^{2}$ & & &
\end{tabular}




\section{HASIL DAN DISKUSI}

\subsection{Uji Kuat Tekan}

Pengaruh variasi gipsum terhadap kuat tekan papan komposit dengan persentasi serat tetap 2,5\% dapat dilihat pada Gambar 1. Pada papan komposit tanpa serat nilai kuat tekannya paling kecil yaitu $6,57 \mathrm{~kg} / \mathrm{cm}^{2}$. Nilai kuat tekan mulai meningkat pada papan komposit dengan serat yaitu $14,18 \mathrm{~kg} / \mathrm{cm}^{2}$,pada persentase gipsum $25 \%$. Nilai kuat tekan paling besar diperoleh pada papan komposit dengan persentasi gipsum $30 \%$ yaitu sebesar $14,52 \mathrm{~kg} / \mathrm{cm}^{2}$. Nilai kuat tekan mengalami penurunan pada persentase $32,5 \%$ dan $35 \%$ menjadi $13,8 \mathrm{~kg} / \mathrm{cm}^{2}$ dan 10,54 $\mathrm{kg} / \mathrm{cm}^{2}$. Dari hasil ini dapat dilihat bahwa nilai optimum kuat tekan papan komposit diperoleh pada persentase gipsum 30\%, namun hasil ini masih di bawah standar SNI 03-6384-2000 yaitu $\min 18 \mathrm{~kg} / \mathrm{cm}^{2}$. Pengaruh massa gipsum terhadap kuat tekan dengan serat tetap 2,5\% dapat dilihat pada Gambar 2.

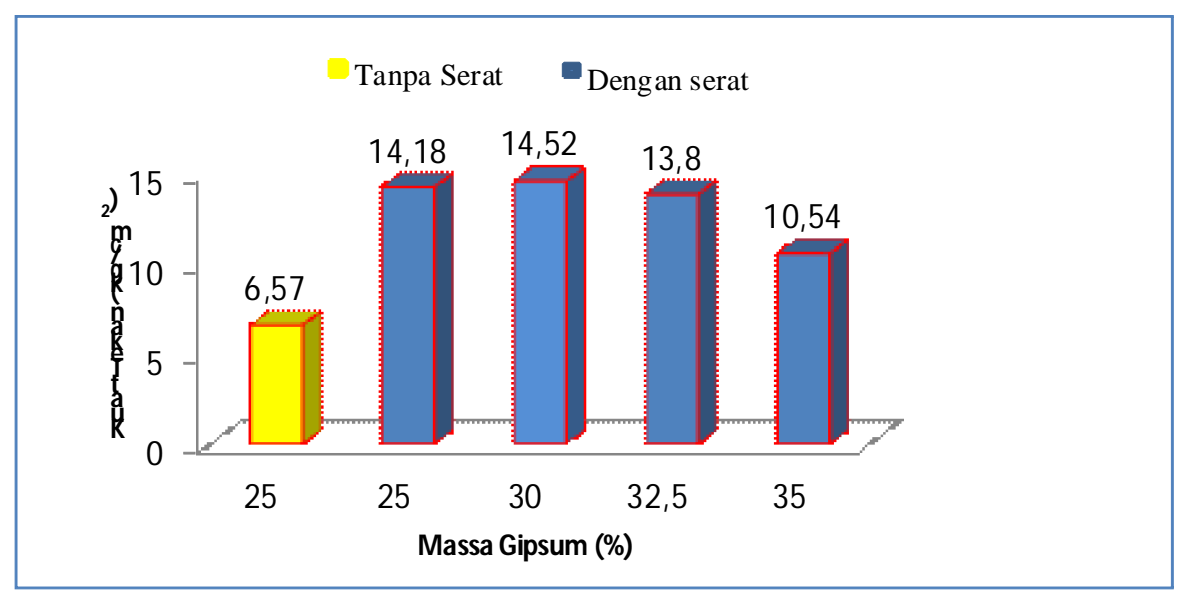

Gambar 1 Pengaruh massa gipsum terhadap kuat tekan dengan serat tetap 2,5\%

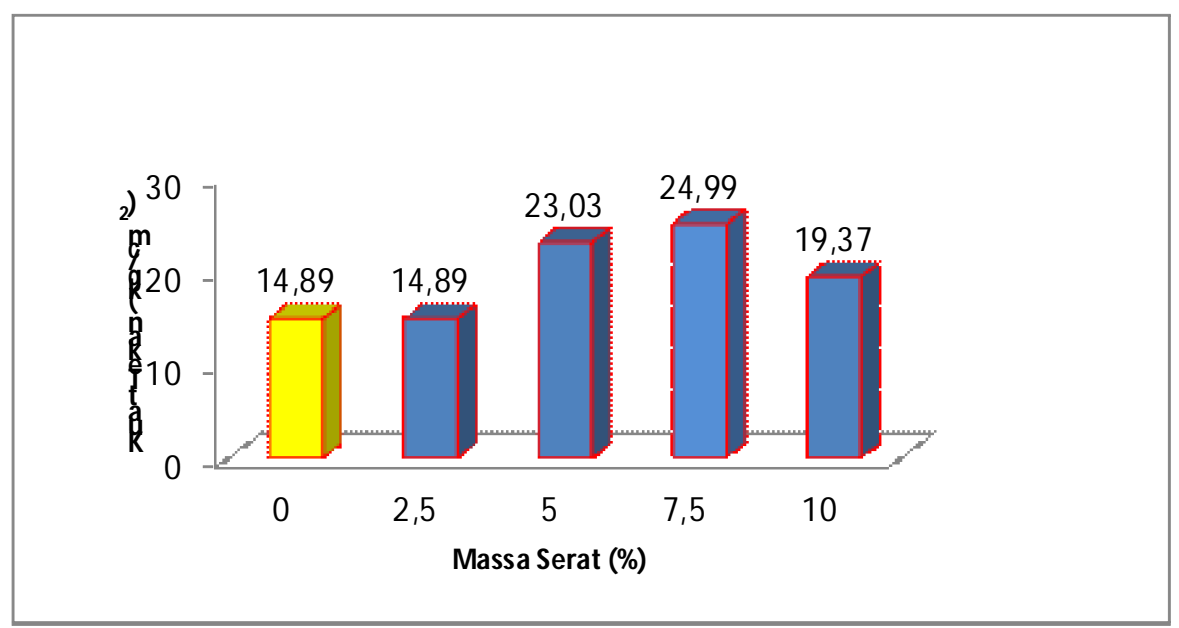

Gambar 2 Pengaruh massa serat terhadap kuat tekan dengan gipsum tetap 30\%

\subsection{Uji Kuat Lentur}

Pengaruh variasi gipsum terhadap kuat lentur papan komposit dengan persentase serat tetap 2,5\% dapat dilihat pada Gambar 3. Nilai kuat tekan meningkat hingga persentase gipsum $30 \%$ kemudian turun pada penambahan gipsum 32,5\% namun naik kembali pada persentase gipsum maka semakin meningkat nilai kuat lentur yang didapat. Hasil penelitian ini belum sesuai dengan standar SNI 03-6384-2000 yaitu $\min 15000 \mathrm{~kg} / \mathrm{cm}^{2}$. Pengaruh kuat lentur terhadap variasi gipsum dengan serat tetap 2,5\% dapat dilihat pada Gambar 4. Pada persentase serat $2,5 \%$ diperoleh nilai optimum kuat lentur yaitu $1,575 \mathrm{~kg} / \mathrm{cm}^{2}$. Sedangkan pada persentase serat $10 \%$ nilai kuat lentur $1,17 \mathrm{~kg} / \mathrm{cm}^{2}$.Hal ini disebabkan semakin bertambahnya serat semakin 
kecil kerapatan papan beton yang menyebabkan pengujian kuat lentur peregangan kelenturan mengecil. Hasil penelitian ini tidak sesuai dengan standar SNI 03-6384-2000 yaitu min 15000 $\mathrm{kg} / \mathrm{cm}^{2}$. Pengaruh massa gipsum terhadap kuat lentur dengan serat tetap 2,5\% dapat dilihat pada Gambar 4.

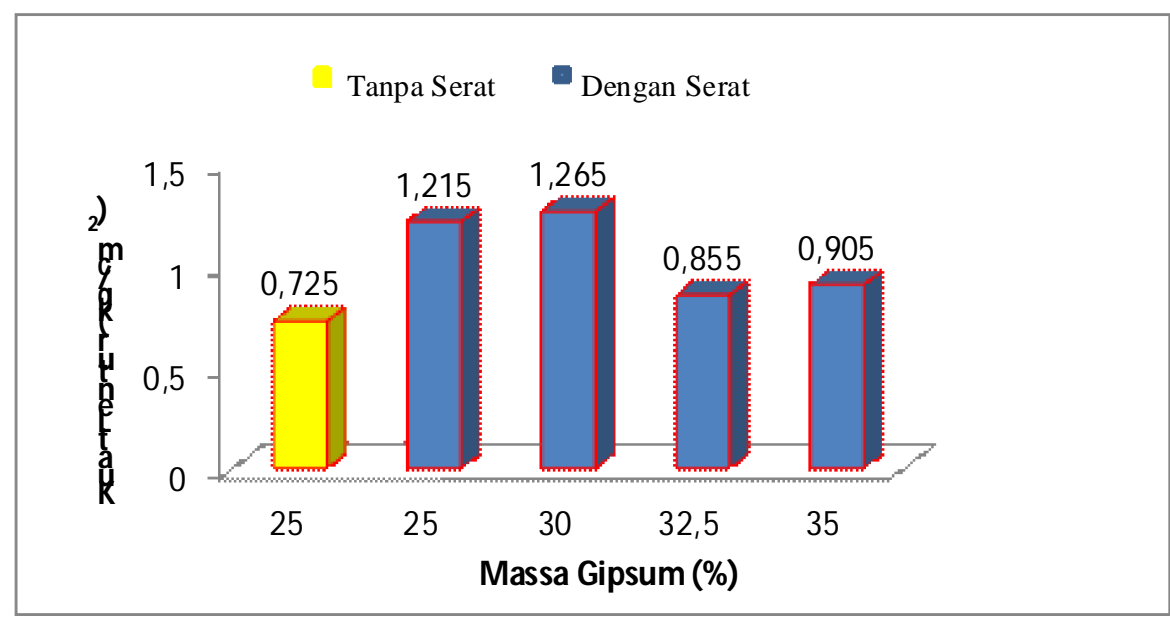

Gambar 3 Pengaruh massa gipsum terhadap kuat lentur dengan serat tetap 2,5\%

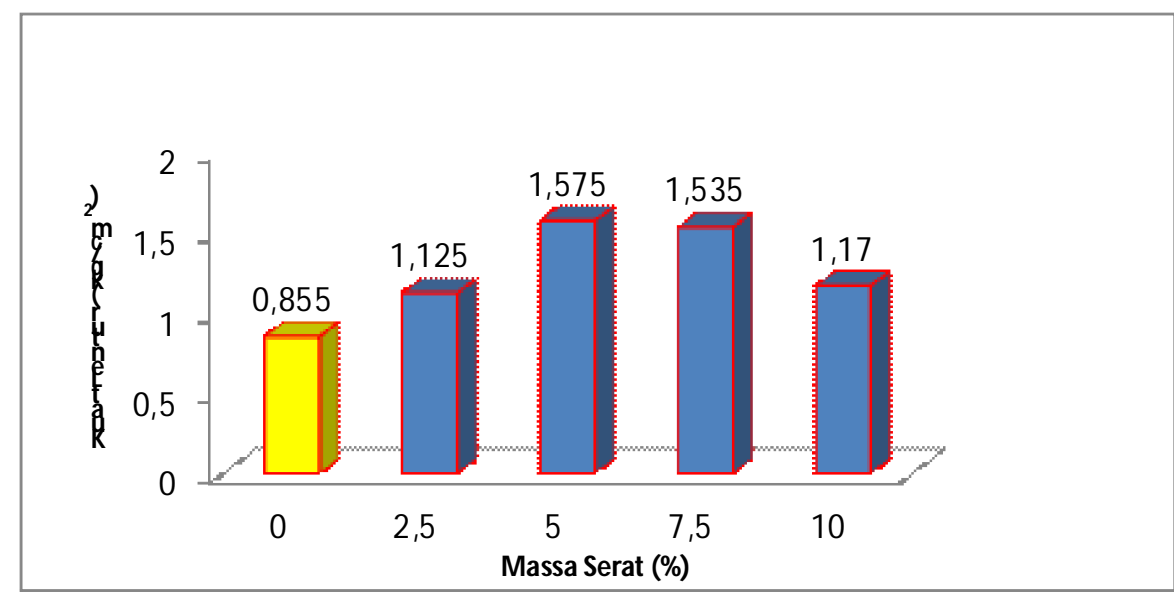

Gambar 4 Pengaruh massa serat terhadap kuat lentur dengan gipsum tetap 30\%

\section{KESIMPULAN}

Dari penelitian yang telah ada dapat disimpulkan bahwa, kuat tekan papan komposit terhadap massa gipsum dengan serat tetap $2,5 \%$ adalah $14,18 \mathrm{~kg} / \mathrm{cm}^{2}-10,54 \mathrm{~kg} / \mathrm{cm}^{2}$. Untuk papan kompsit tanpa serat diperoleh nilai kuat tekan sebesar $6,57 \mathrm{~kg} / \mathrm{cm}^{2}$. Pada papan komposit dengan massa serat dan gipsum tetap $30 \%$ diperoleh nilai kuat tekan $14,89 \mathrm{~kg} / \mathrm{cm}^{2}-24,99$ $\mathrm{kg} / \mathrm{cm}^{2}$,sedangkan tanpa serat $14,89 \mathrm{~kg} / \mathrm{cm}^{2}$. Kuat lentur terhadap variasi gipsum dengan serat tetap $2,5 \%$ sebesar yaitu $1,215 \mathrm{~kg} / \mathrm{cm}^{2}-0,855 \mathrm{~kg} / \mathrm{cm}^{2}$ tanpa serat sebesar $0,725 \mathrm{~kg} / \mathrm{cm}^{2}$. Pada variasi serat dengan gipsum tetap $30 \%$ yaitu $1,125 \mathrm{~kg} / \mathrm{cm}^{2}-1,17 \mathrm{~kg} / \mathrm{cm}^{2}$. Sedangkan tanpa serat $0,855 \mathrm{~kg} / \mathrm{cm}^{2}$.

\section{DAFTAR PUSTAKA}

Kahfi, F., Sifat Fisis Mekanis Papan Gipsum dari Tandan Kososng Kelapa Sawit (Elaeis guineensis Jacq) dengan Perlakuan Perendaman dan Variasi Kadar Gipsum, Skripsi, Departemen Kehutanan, Universitas Sumatera Utara Medan, 2007.

Nugraha, P., dan Antoni.,Teknologi Beton, dari Material Pembuatan Ke Beton Kinerja Tinggi,Universitas Kristen Petra. Yogyakarta, 90-98 (2007).

Prasetyo, L., Pemanfaatan Batang Eceng Gondok Untuk Material Bahan Bangunan, Makalah Seminar Nasional, Universitas Muhammadiyah, Malang, 2006. 
Prasetyo, L., Daktilisasi Panel Semen Eceng Gondok, Makalah Seminar Nasional, Universitas Muhammadiyah, Malang, 2009.

Roseno, Seto.,Serat Alam Sebagai Penguat Produk Komposit Ramah Lingkungan. Pusat Teknologi Material, BPPT, Jakarta, 2008.

Simatupang, M.H., Lange. H, Kasim. A., eddig. N., "Influence Of Wood Species On The Setting Of Cement and Gypsum". Didalam: Moslemi AA, Hamel MP, editor, Proceedings Fiber and Particle Boards Bonded with Inorganic Binders, 33-42 (1989)

Smallman, R. E., dan Bishop R. J.,"Matalurgi Fisik Modern dan Rekayasa Material",Edisi Keenam, Erlangga. Jakarta,156-157 (2010). 